Journal for ImmunoTherapy of Cancer

\title{
Metabolic features of cancer cells impact immunosurveillance
}

\author{
Adrien Joseph (D) , ${ }^{1,2,3}$ Pan Juncheng, ${ }^{1,2,3}$ Michele Mondini, ${ }^{4}$ Nizar Labaied, ${ }^{5}$ \\ Mauro Loi, ${ }^{6}$ Julien Adam, ${ }^{7,8}$ Antoine Lafarge, ${ }^{1,2,3}$ Valentina Astesana, ${ }^{1,2,3}$ \\ Florine Obrist, ${ }^{1,2,3}$ Christophe Klein, ${ }^{9}$ Norma Bloy, ${ }^{1,2,3}$ Gautier Stoll, ${ }^{1,2}$ \\ Nicolas Signolle, ${ }^{5}$ Catherine Genestie, ${ }^{5}$ Diane Damotte, ${ }^{10}$ Marco Alifano, ${ }^{11}$ \\ Alexandra Leary, ${ }^{12}$ Patricia Pautier, ${ }^{12}$ Philippe Morice, ${ }^{13}$ Sebastien Gouy, ${ }^{13}$ \\ Eric Deutsch, ${ }^{14}$ Cyrus Chargari, ${ }^{14}$ Marie-Caroline Dieu-Nosjean, ${ }^{15}$ \\ Isabelle Cremer (D) , ${ }^{16}$ Judith Michels, ${ }^{17}$ Guido Kroemer, ${ }^{1,18,19,20}$ Maria Castedo ${ }^{1,2}$
}

To cite: Joseph A, Juncheng P, Mondini M, et al. Metabolic features of cancer cells impact immunosurveillance. Journal for Immunotherapy of Cancer 2021;9:e002362. doi:10.1136/ jitc-2021-002362

- Additional supplemental material is published online only. To view, please visit the journal online (http://dx.doi.org/10. 1136/jitc-2021-002362).

Accepted 20 May 2021

Check for updates

(c) Author(s) (or their employer(s)) 2021. Re-use permitted under CC BY-NC. No commercial re-use. See rights and permissions. Published by BMJ.

For numbered affiliations see end of article.

\section{Correspondence to}

Dr Maria Castedo, INSERM

U1138 Equipe 11, Centre de

Recherche des Cordeliers,

75006 Paris, lle-de-France,

France;

maria.castedo-delrieu@ sorbonne-universite.fr

Guido Kroemer; kroemer@orange.fr

Dr Judith Michels; michelsjudith@gmail.com

\section{ABSTRACT}

Background Tumors rewire their metabolism to achieve robust anabolism and resistance against therapeutic interventions like cisplatin treatment. For example, a prolonged exposure to cisplatin causes downregulation of pyridoxal kinase (PDXK), the enzyme that generates the active vitamin $\mathrm{B} 6$, and upregulation of poly ADP-ribose (PAR) polymerase-1 (PARP1) activity that requires a supply of nicotinamide (vitamin B3) adenine dinucleotide. We investigated the impact of the levels of PDXK and PAR on the local immunosurveillance (ie, density of the antigen presenting cells and adaptive immune response by CD8 T lymphocytes) in two different tumor types.

Methods Tumors from patients with locally advanced cervical carcinoma (LACC) and non-small cell lung cancer (NSCLC) were stained for PAR, PDXK, dendritic cell lysosomal associated membrane glycoprotein (DCLAMP) and CD8 T cell infiltration. Their correlations and prognostic impact were assessed. Cisplatin-resistant NSCLC cell clones isolated from Lewis-lung cancer (LLC) cells were evaluated for PAR levels by immunoblot. Parental (PAR ${ }^{\text {low }}$ ) and cisplatin-resistant $\left(\right.$ PAR $\left.^{\text {high }}\right)$ clones were subcutaneously injected into the flank of C57BL/6 mice. Tumors were harvested to evaluate their immune infiltration by flow cytometry.

Results The infiltration of tumors by CD8 T and DC$\mathrm{LAMP}^{+}$cells was associated with a favorable overall survival in patients with LACC $(p=0.006$ and $p=0.008$, respectively) and NSCLC $(p<0.001$ for both CD8 T and DC-LAMP cells). We observed a positive correlation between PDXK expression and the infiltration by DCLAMP ( $R=0.44, p=0.02$ in LACC, $R=0.14, p=0.057$ in NSCLC), and a negative correlation between PAR levels and CD8 $\mathrm{T}$ lymphocytes $(\mathrm{R}=-0.39, \mathrm{p}=0.034$ in LACC, $\mathrm{R}=-0.18, \mathrm{p}=0.017$ in NSCLC). PARP1 is constitutively hyperactivated in cisplatin-resistant LLC cells manifesting elevated intracellular levels of poly(ADP-ribosyl)ated proteins (PAR $\left.{ }^{\text {high}}\right)$. Tumors formed by such cancer cells injected into immunocompetent mice were scarcely infiltrated by CD8 T $(p=0.028)$ and antigen presenting cells $(p=0.086)$.

Conclusions Oncometabolic features can impact local immunosurveillance, providing new functional links between cisplatin resistance and therapeutic failure.

\section{INTRODUCTION}

Cancer cell-intrinsic properties drive alterations in the microecosystem that is composed by malignant cells, stromal elements as well as tumor-infiltrating leukocytes. This latter point has been neglected for a long time, yet spurred ever expanding interest since the discoveries that (i) the presence of certain immune effectors, in particular $\mathrm{CD}^{+}$cytotoxic $\mathrm{T}$ lymphocytes (CTLs) and activated dendritic cells (DCs) have a major prognostic impact in most extracranial cancer types ${ }^{1}$ and (ii) immunotherapy with antibodies neutralizing the cytotoxic T-lymphocyte associated protein 4 (CTLA-4) and programmed cell death protein 1 (PD-1)/programmed cell death ligand 1 (PD-L1) has the potential to become a close-to-universal antineoplastic treatment. $^{2}$ Today, it is common knowledge that tumors, to become truly life threatening, must fulfill a compendium of conditions including malignancy (ie, the unrestrained proliferation and dissemination of neoplastic cells) and escape from immunosurveillance (ie, camouflage of tumor cells to become invisible to the immune system and/or active immunosuppression). ${ }^{3}$

The metabolic features of tumors may also be interpreted in the sense of a constant dialog between malignant and immune cells. In essence, tumor cells must rewire their metabolisms to produce biomass, initially often in a hostile context with scarce supply of growth factors, glucose, amino acids and oxygen. Beyond these anabolic capacities and an increased capacity to 'capture' nutrients from the environment, oncometabolism also may subvert immunosurveillance (and hence interfere with immunometabolism). For example, lactate produced by malignant cells and low extracellular $\mathrm{pH}$ interfere with $\mathrm{T}$ cell 
functions. ${ }^{4}$ In addition, the expression levels of metabolic enzymes such as aldehyde dehydrogenase 7 family, member A1 (ALDH7A1) are associated with a paucity of immune effectors within the tumor bed, while that of lipase C, hepatic type (LIPC) positively correlates with abundant tumor infiltration by myeloid and lymphoid cells in several different human cancer types. ${ }^{5}$ As an extreme, some cancers have developed the capacity to engulf and cannibalize lymphocytes, thus converting their enemies into nutrients. ${ }^{6}$

Cancer cells can also rewire their metabolism in response to iatrogenic stresses. For example, cisplatinbased chemotherapy causes a selection/adaptation of malignant cells that often leads to the downregulation of the vitamin $\mathrm{B} 6$ activating enzyme pyridoxal kinase $(\mathrm{PDXK})^{7}$ and the upregulation of the enzymatic activity of poly(ADP-ribose) (PAR) polymerase (PARP1) that requires a supply of nicotinamide adenine dinucleotide (NAD) ${ }^{8}$ Nicotinamide is also known as vitamin B3. These alterations are causatively involved in cisplatin resistance because re-expression of PDXK or depletion/inhibition of PARP1 restores cisplatin sensitivity of cancer cells. ${ }^{79}$ Moreover, low PDXK expression or high abundance of the PARP1 product PAR within malignant cells indicates poor prognosis in patients with non-small cell lung cancer (NSCLC). ${ }^{710}$

Here, we investigated the possibility that markers of the vitamin B metabolism, namely PDXK and PAR, would affect the density of the antigen presenting cells (ie, DCs measured by dendritic cell lysosomal associated membrane glycoprotein (DC-LAMP)) and the adaptive immune response as measured by the density of the CD8 $\mathrm{T}$ cells, in locally advanced cervical squamous cell carcinoma, which is known to be under CTL-mediated surveillance, ${ }^{11-13}$ and NSCLC, for both of which cisplatin still belongs to the standard of care.

\section{MATERIALS AND METHODS}

\section{Patients and survival data}

The cohort of patients with cervical cancer $(n=66)$ included paraffin-embedded baseline tumor biopsies from patients with locally advanced cervical cancer (LACC) undergoing curative-intent concurrent chemoradiation followed by uterovaginal brachytherapy boost. They were treated in our institution between March 2004 and August 2011. ${ }^{14}$ Only squamous cell carcinomas, which is the most frequent histology, were included in the analysis. A second cohort of paraffin-embedded baseline NSCLC surgical samples was evaluated from patients (stage I to III-IV according to 7th edition TNM classification) undergoing primary surgery at Hôtel-Dieu Hospital (Paris, France) between 2001 and 2005. ${ }^{15}$ All tumor specimens were collected before chemotherapy. The patients' main clinical and pathological features are described in online supplemental tables S1 and S2. A written informed consent was obtained from all patients, in application with the article L.1121-1 of French law and the two studies were approved by the local ethics committee (CPP 2012-0612).

Pearson's correlation coefficients with their significance value were calculated and depicted in scatter plots. Kaplan-Meier curves were stratified using the median value of the cohort for PAR and PDXK expression and DC-LAMP and CD8 infiltration and the log-rank test was used to compare overall and relapse-free survival of patients between groups. The start of follow-up was the date of biopsy for patients with LACC and NSCLC. Statistical testing was done at the two-tailed $\alpha$ level of 0.05 . Statistics were managed using R software V.3.4.2 (R Foundation for Statistical Computing, Vienna, Austria; https:// www.R-project.org/, packages survival, survminer, Hmisc and corrplot).

\section{IMMUNOHISTOCHEMISTRY}

In the lung cancer cohort, tumor samples were fixed in neutral buffered $10 \%$ formalin solution and paraffin embedded. Tumors were freshly cut for immunohistochemical analysis, paraffin section was dewaxed, followed by antigen retrieval with Target Retrieval Solution (Dako) in a preheated water bath $\left(98^{\circ} \mathrm{C}, 30 \mathrm{~min}\right)$. Sections were cooled at room temperature for $30 \mathrm{~min}$ and endogenous peroxidase was blocked with 3\% hydrogen peroxide. Thereafter, sections were incubated with diluted $5 \%$ human serum for $30 \mathrm{~min}$ and incubated with PAR (AM80, Calbiochem), PDXK (AP7167a, Abgent), DC-LAMP (DDX0191, clone 1010E1.01) and CD8 (clone SP16, Spring Bioscience) antibodies. We chose to evaluate PAR activity and not protein expression because, as previously shown, low PARP1 protein levels do not preclude a high activity of this enzyme ${ }^{10}$ and PARP1 expression do not correlate with survival. ${ }^{16}$ PAR and PDXK were manually evaluated by trained observers. In the NSCLC cohort, 186 samples were available for PAR/PDXK staining. The correlations were calculated according to the median (ie, marker ${ }^{\text {high }}$ equivalent or superior to the median, marker $^{\text {low }}$ is less than the median). DC-LAMP ${ }^{+}$cells were counted manually by two trained observers on five selected regions of interest and expressed as an absolute number of positive cells $/ \mathrm{mm}^{2}$ (density) of tumor. CD8 positive cells were counted using Visiopharm image analysis software on the same five manually selected regions of interest and expressed as an absolute number (density) of positive cells $/ \mathrm{mm}^{2}$ of tumor.

\section{SCORING OF EXPRESSION LEVELS}

Staining percentage of reactive tumor cells was scored on a $0 \%-100 \%$ scale for PDXK and PAR. The correlations and survival were calculated according to the median (ie, marker ${ }^{\text {high }}$ equivalent or superior to the median, marker ${ }^{\text {low }}$ is less than the median). The median value for the five regions of the density for DC-LAMP ${ }^{+}$and CD8 was taken into account for the survival and correlation analyses. 


\section{Cell lines, culture conditions and chemicals}

Culture media and cell culture supplements were purchased from Life Technologies (Carlsbad, California, USA). Cells were routinely maintained at $37^{\circ} \mathrm{C}$ under $5 \%$ $\mathrm{CO}_{2}$, in the following culture medium: Dulbecco's modified Eagle's medium supplemented with $10 \%$ fetal bovine serum, 100 units $/ \mathrm{mL}$ penicillin G sodium and $100 \mathrm{mg} / \mathrm{mL}$ streptomycin sulfate. Mouse Lewis lung carcinoma (LLC) cell line was purchased from American Type Culture Collection. Cisplatin-resistant clones were obtained in vitro by prolonged culture of parental (also known as wild type (WT)) cells with sublethal concentrations of cisplatin (Sigma-Aldrich). In parallel, control clones were obtained from the untreated WT cells. Both parental and cisplatin-resistant cells were never passaged more than 1 month before use in experimental determinations.

\section{Quantification of apoptotic features}

Adherent and non-adherent cells were collected and costained for $30 \mathrm{~min}$ at $37^{\circ} \mathrm{C}$ in $300 \mu \mathrm{L}$ of culture medium
A

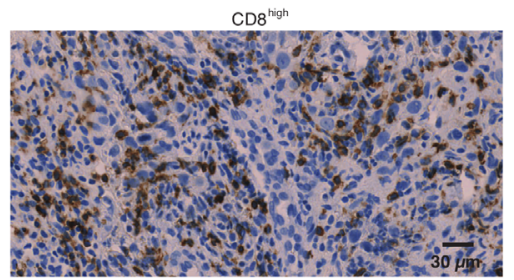

C
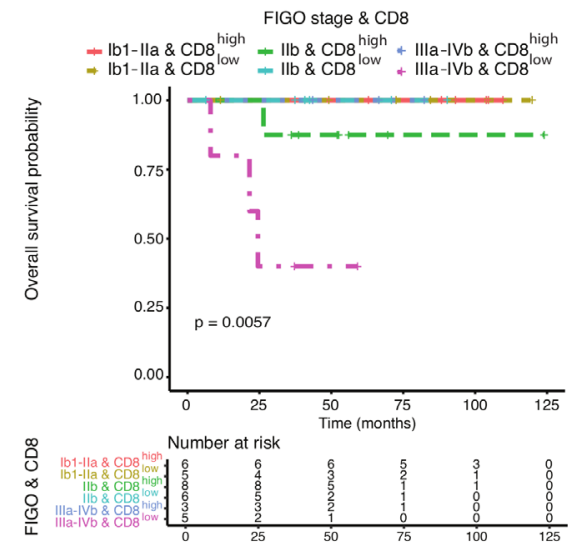

E

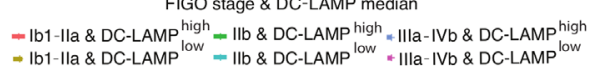
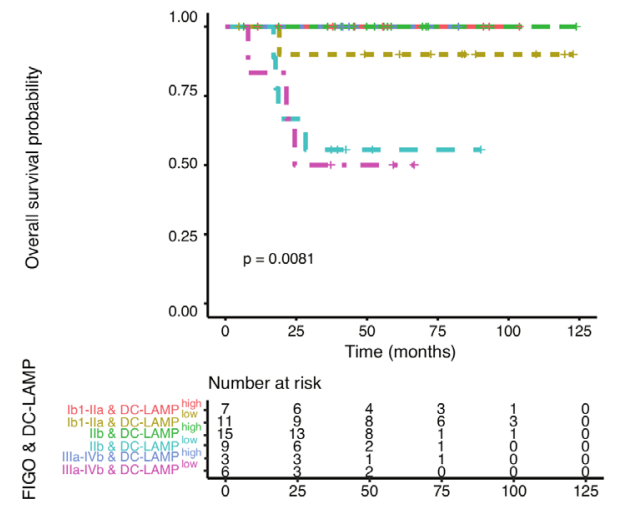

B

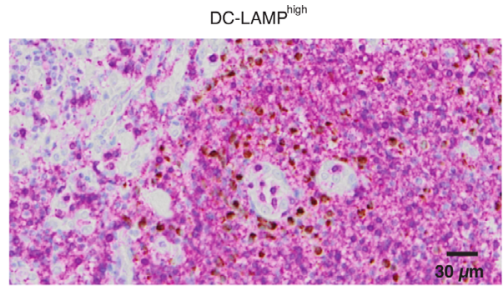

D

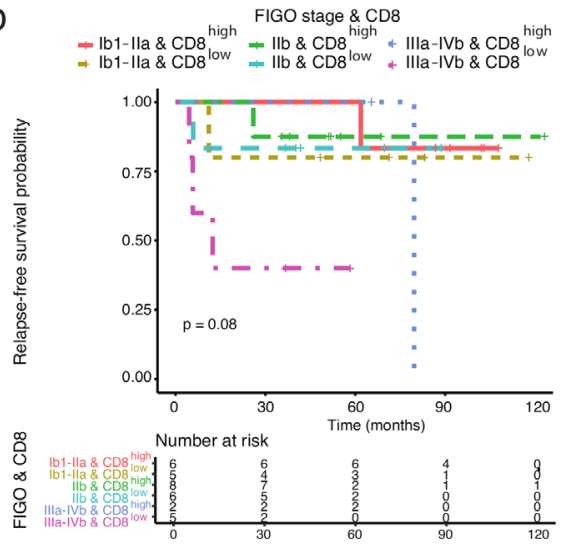

F FIGO stage \& DC-LAMP median - Ib1-Ila \& DC-LAMP high - Ilb \& DC-LAMPhigh • Illa-IVb \& DC-LAMP hig - Ib1-Ila \& DC-LAMP ${ }^{\text {low }}=11 \mathrm{ll}$ \& DC-LAMP ${ }^{\text {low }}$ *Illa-IVb \& DC-LAMP ${ }^{\text {low }}$
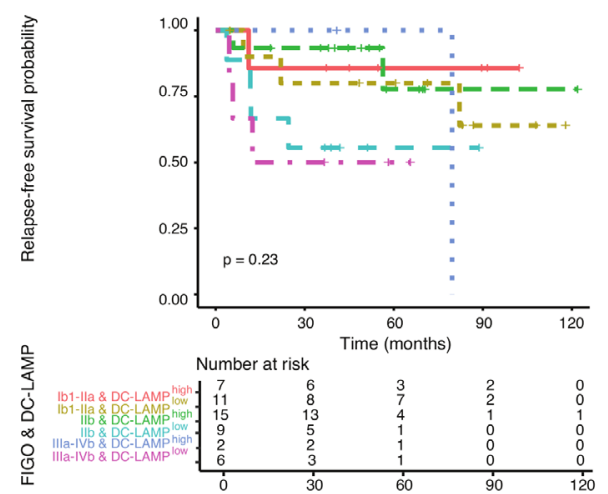

Figure 1 Prognostic value of CD8 and DC-LAMP stratification in patients with locally advanced squamous cell cervical cancer. (A-B) Immunohistochemical detection of CD8 (A) and DC-LAMP ${ }^{+}(B)$ cells with high density in resected cervical cancer tumors. CD8 or DC-LAMP ${ }^{+}$positive cells are shown in brown. Representative images are reported (scale bare=30 $\left.\mu m\right)$. (C-D, E-F) Kaplan-Meier curves of overall survival and relapse-free survival on stratification of patients according to FIGO stage and CD8 (C,D) or FIGO stage and DC-LAMP (E,F) median expression, respectively. P values were determined by means of the logrank test. Tables summarize the number of patients at risk in each group at baseline and at several time points. Two-by-two comparisons only show a significant survival and relapse-free survival advantage for DC-LAMP infiltration in FIGO IIb tumors $(p=0.006)$. DC-LAMP, dendritic cell lysosomal associated membrane glycoprotein; FIGO, International Federation of Gynecology and Obstetrics. 
A

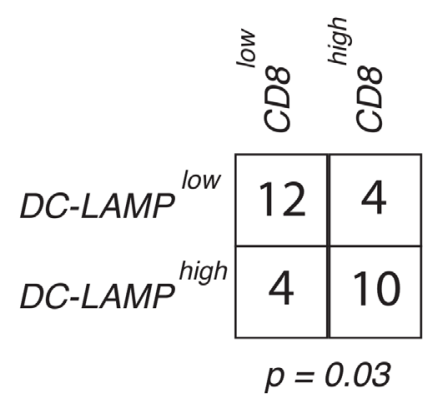

C

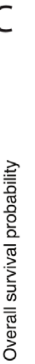
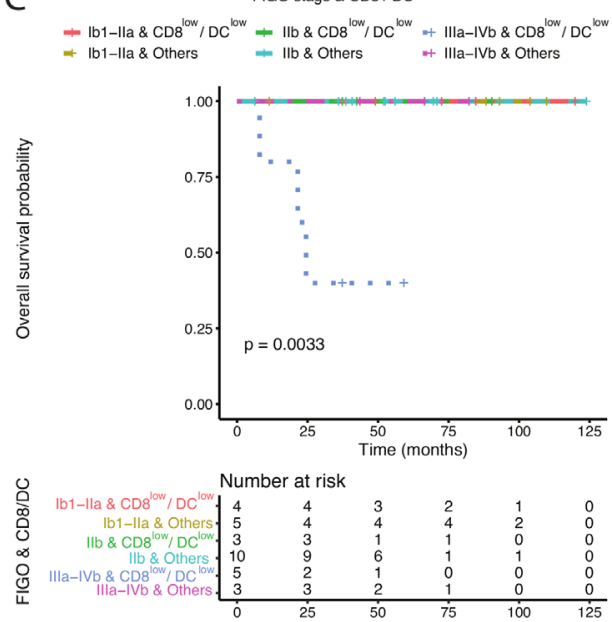

B

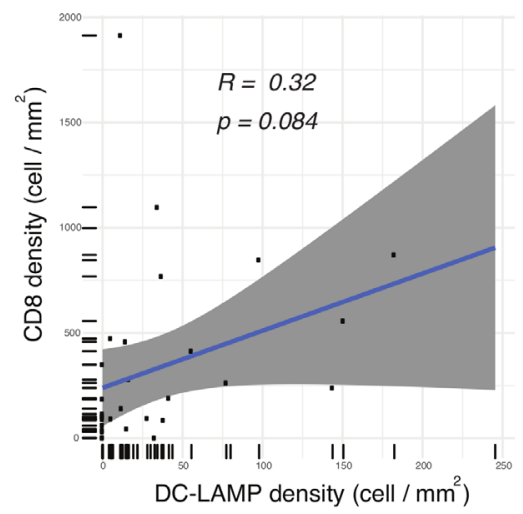

D

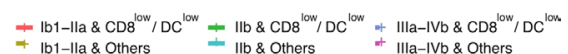
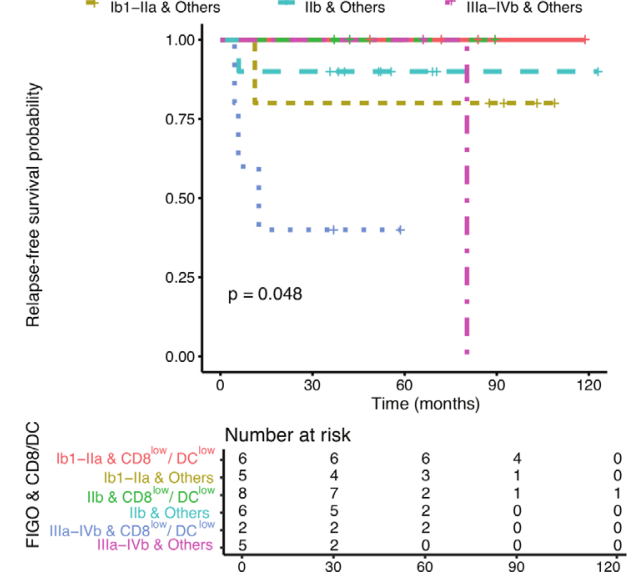

Figure 2 Correlation between CD8 and DC-LAMP in patients with locally advanced squamous cell cervical cancer. (A) Number of patients in each group at baseline as determined by immunohistochemistry. Distribution in CD8 and DC-LAMP groups were compared by means of the $\chi^{2}$ test. (B) Correlation between CD8 and DC-LAMP densities. A total of 30 patients' samples were evaluable. Each point represents one patient, with rug added on $X$ and $Y$ axis. The regression line from a linear regression model between CD8 and DC-LAMP densities is depicted in blue with its $95 \% \mathrm{Cl}$ in gray. P values were based on Pearson's product moment correlation coefficient. (C,D) Kaplan-Meier curves of overall survival (C) and relapse-free survival (D) on stratification of patients according to FIGO stage and CD8 ${ }^{\text {low }} / D C-L A M P^{\text {low }}$ status. Tables summarize the number of patients at risk in each group at baseline and at several time points. DC-LAMP, dendritic cell lysosomal associated membrane glycoprotein; FIGO, International Federation of Gynecology and Obstetrics.

containing $40 \mathrm{nM}$ 3,3' dihexiloxalocarbocyanine iodide $\left(\mathrm{DiOC}_{6}(3)\right)$, Molecular Probes-Invitrogen), a mitochondrial transmembrane potential-sensitive dye, and $1 \mu \mathrm{g} /$ $\mathrm{mL}$ propidium iodide, which only accumulates in cells exhibiting plasma membrane permeabilization. Cytofluorometric acquisitions were carried out on a Milteny cytofluorometer (MACSQuant Analyzer 10), and statistical analyses were performed by using the FlowJo software (LLC, Oregon, USA) on gating on events exhibiting normal forward scatter and side scatter parameters.

\section{Immunoblotting}

Cells were trypsinized, collected, washed twice with phosphate-buffered saline (PBS) and lysed in a buffer containing $50 \mathrm{mM}$ Tris $\mathrm{HCl} \mathrm{pH} 6.8$, glycerol $10 \%, 2 \%$ Sodium dodecyl sulfate (SDS), $10 \mathrm{mM}$ ithiothréitol (DTT) and $0.005 \%$ bromophenol blue. Subsequently, $30 \mu \mathrm{g}$ of proteins were separated on $4 \%-12 \%$ sodium dodecyl sulfate polyacrylamide gel electrophoresis (SDS-PAGE) gels (Invitrogen) and electrotransferred to nitrocellulose membranes (Biorad) followed by immunoblotting with a primary antibody specific for PAR (Clone 10H, mAb to poly ADP-ribose, Abcam, 1:1000). An antiactin antibody (mAb to beta actin, ab 49900, Abcam, 1:5000) was used to control equal lane loading. Thereafter, membranes were incubated with appropriate horseradish peroxides-conjugated secondary antibodies (Southern Biotech), followed by chemiluminescence detection with the ECLTM Prime Western Blotting Detection Reagent (GE Healthcare), before being revealed by the ImageQuantTM LAS 4000 Biomolecular Imager (GE Healthcare Life Sciences). Finally, protein expression was quantified by ImageJ software (NIH, USA).

\section{Mouse housing and murine cancer model}

Eight-week-old female C57Bl/6 mice were purchased from Envigo France. Animals were maintained in specific pathogen-free conditions, at $25^{\circ} \mathrm{C}$ with 12 hours light/12 hours dark cycles. All animals were used under an approved protocol by the local Ethics Committee (C2EA 
A

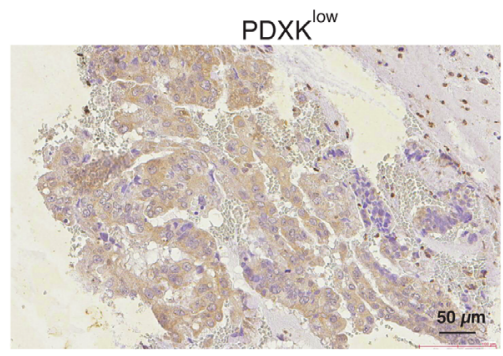

C

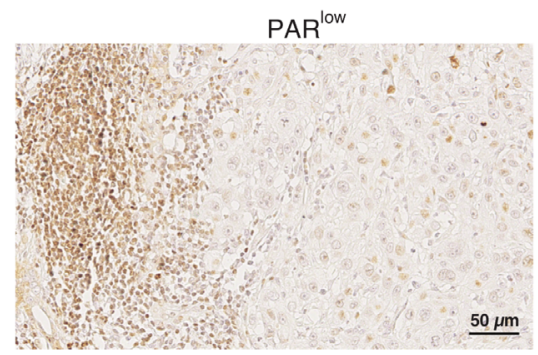

$\mathrm{E}$

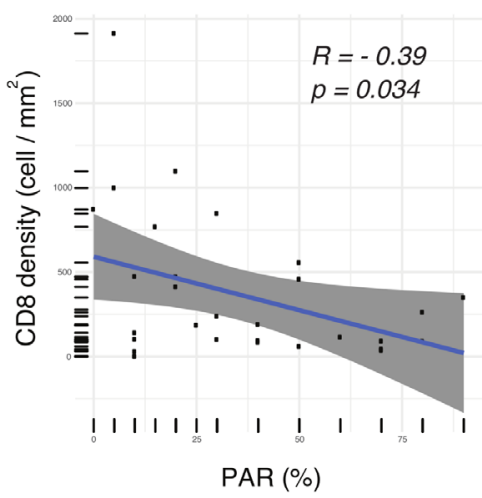

B

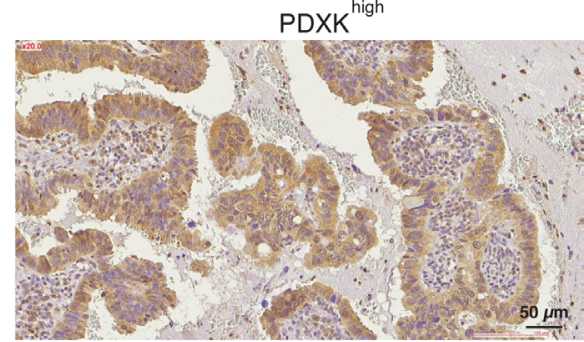

D

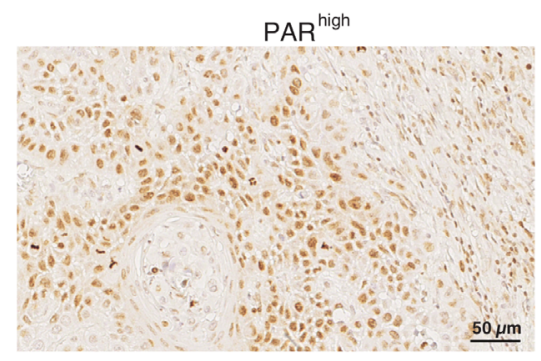

$\mathrm{F}$

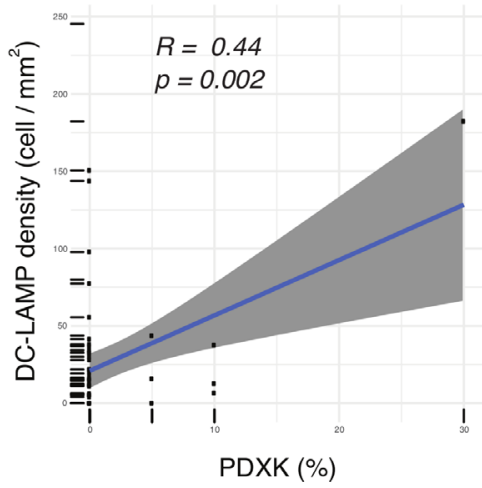

Figure 3 Immunohistochemical detection of PDXK (A,B) and PAR (C,D) cells in locally advanced squamous cell carcinoma samples. Note in (C) the presence of lymphocytes (left side) that were used as an internal positive control. Representative images are reported (scale bare= $50 \mu \mathrm{m})$. (E,F) Correlations between PDXK and DC-LAMP density (F) or PAR and CD8 density $(F)$, as determined by immunohistochemistry with specific antibodies on biopsies from patients with cervical cancer, followed by calculation of Pearson's correlation coefficient. Each point represents one patient, with rug added on X and Y axes. The regression line from a linear regression model between CD8 and DC-LAMP densities is depicted in blue with its $95 \% \mathrm{Cl}$ in gray. $\mathrm{P}$ values were based on Pearson's product moment correlation coefficient. DC-LAMP, dendritic cell lysosomal associated membrane glycoprotein; PAR, poly adenosine ribose; PDXK, pyridoxal kinase.

$05 \mathrm{n}^{\circ}$ B-75-06-12, protocol 7810-2016112810578922v2) under conditions in accordance with the EU Directive $63 / 2010$. Sample sizes were calculated to detect a statistically significant effect. For tumor induction, 1.2-1.7 $\times 10^{6}$ WT and cisplatin-resistant (R) LLC cells were resuspended in $100 \mu \mathrm{L}$ of PBS and subcutaneously injected in the flank of mice under anesthesia (2.5\% isoflurane). The estimation of the tumor area (longest dimension $x$ perpendicular dimension) was measured using a common caliper. Tumor ulceration, weight loss superior to $20 \%$ as compared with the beginning of the treatment and poor body condition were considered as endpoints.

\section{Ex vivo analysis of mouse tumor immune infiltrate}

When the surface of the tumors derived from WT and cisplatin-resistant LLC cells reached $1 \mathrm{~cm}^{2}$, corresponding to approximately 30 days after tumor cells injection, tumors were harvested, weighed and transferred on ice in
gentleMACS C tubes (Miltenyi Biotec, USA) containing $1 \mathrm{~mL}$ Dulbecco's modified eagle medium (DMEM) medium. Tumors were dissociated mechanically with scissors, then enzymatically using the Miltenyi Biotec mouse tumor dissociation kit and a gentleMACS Octo Dissociator following the manufacturer's instructions. Then, the homogenates were filtered through $70 \mu \mathrm{m}$ MACS SmartStrainers (Miltenyi Biotec) and washed twice with PBS. Thereafter, tumor cells were resuspended in PBS and $50 \mathrm{mg}$ of the initial tumor sample were stained with LIVE/DEAD Fixable Yellow dye (Thermo Fisher Scientific). Fc receptors were blocked with anti-mouse CD16/CD32 (clone 2.4G2, Mouse BD Fc Block, BD Pharmingen). Surface staining of murine T-cell population infiltrating the tumor was performed with the following fluorochrome-conjugated antibodies: antiCD3 APC V450 (clone 17A2, Thermo Fisher Scientific), 
A

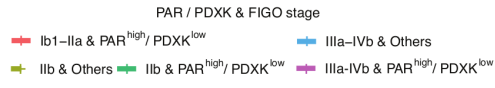

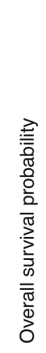

B
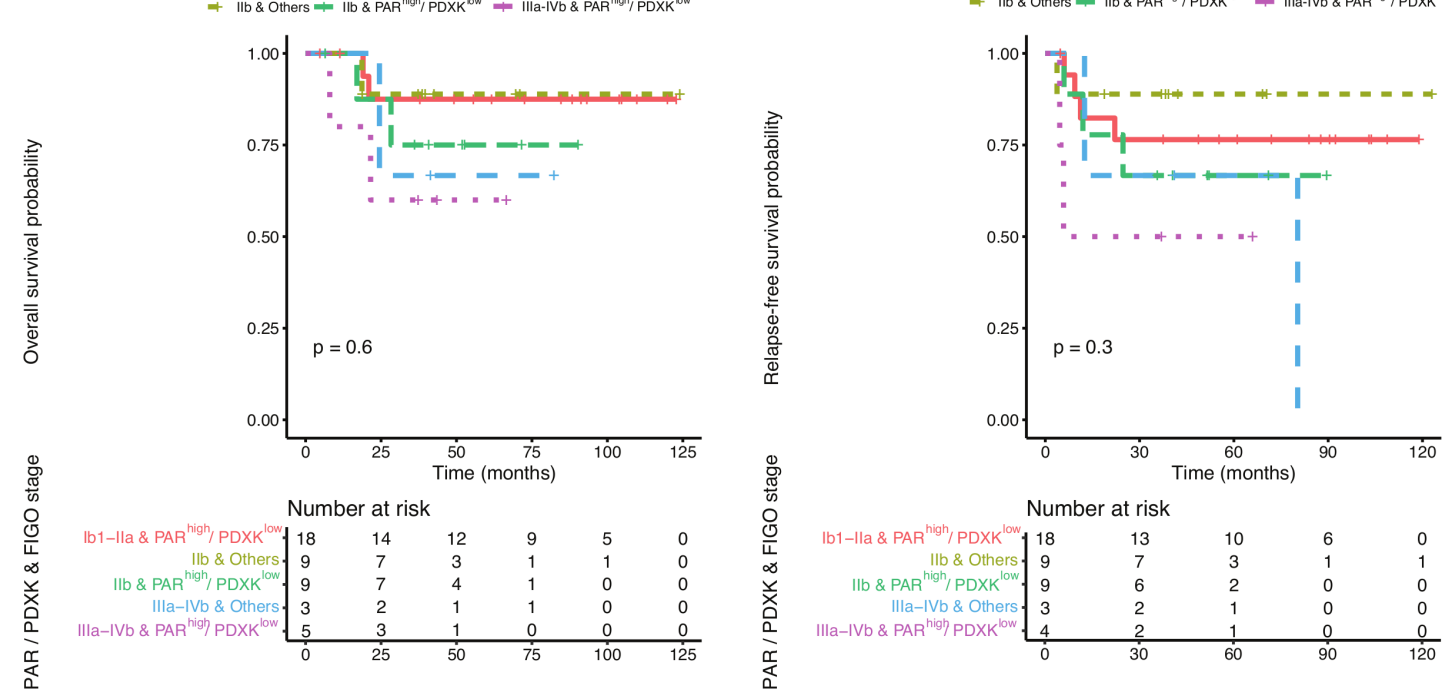

Figure 4 Kaplan-Meier curves of overall survival (A) and relapse-free survival (B) on stratification of patients with advanced squamous cell cervical cancer according to FIGO stage and PAR ${ }^{\text {high }} / \mathrm{PDXK}^{\mathrm{low}}$ status. P values were determined by means of the log-rank test. Tables summarize the number of patients at risk in each group at several time points. Two-by-two comparisons show non-significant poorer overall survivals in PAR ${ }^{\text {high }} / \mathrm{PDXK}^{\text {low }}$ tumors compared with others in both FIGO stage Ilb $(p=0.5)$ and stage IIla-IVb $(p=0.7)$ and relapse-free survivals in PAR ${ }^{\text {high }} / P D X K^{\text {low }}$ tumors FIGO stage Illb $(p=0.3)$ and stage Illa-IVb $(p=0.3)$. FIGO, International Federation of Gynecology and Obstetrics; PAR, poly adenosine ribose; PDXK, pyridoxal kinase.

anti-CD8 PE (clone 53-6.7, BD Pharmingen). Myeloid populations were stained with the following antibodies: anti-CD45 APC-Fire750 (clone 30F-11, BioLegend), anti-Ly-6G PE (clone 1A8, BD Pharmingen), anti-Ly-6C FITC (clone AL-21, BD Pharmingen), anti-CD11b V450 (clone M1/70, BD Pharmingen), anti-CD11c PE-Vio770 (REA754, Miltenyi Biotec) and anti-I-A/E (MHC-II) APC (clone M5/114.15.2, BioLegend). Finally, stained samples were run through a BD LSR II flow cytometer. Data were acquired using BD FACSDiva software (BD biosciences) and analyzed using FlowJo software (TreeStar).

\section{RESULTS}

\section{Relationship between the immune infiltrate and metabolic} parameters in patients with LACC

We found a positive effect of tumor infiltration by $\mathrm{CD} 8^{+}$ $\mathrm{T}$ lymphocytes (determined by immunohistochemistry, figure 1A) to be associated with improved overall survival (figure 1C) and a trend for improved relapsefree survival (figure 1D) in patients with LACC stratified by tumor stage. We also determined the density of the tumor infiltrating DC-LAMP ${ }^{+}$cells (which are activated DCs) by immunohistochemistry (figure 1B). None of the women with a DC-LAMP ${ }^{\text {high }}$ tumor died, meaning that high DC-LAMP ${ }^{+}$density was significantly $(p=0.0081$, log-rank test) associated with overall survival (figure 1E) as well as a tendency for improved relapse-free survival (figure 1F) (online supplemental table S3). DC-LAMP ${ }^{\text {high }}$ tumors were densely infiltrated by $\mathrm{CD}^{+} \mathrm{T}$ cells $(\mathrm{p}=0.03$ by $\chi^{2}$ test, $\mathrm{p}=0.08$ when computed as continuous values) (figure 2A,B). The combination of a low infiltration by both CD8 and DCs carried a significantly worse prognosis compared with tumors highly infiltrated $(\mathrm{p}=0.003$, logrank test) (figure 2C,D). We also determined the expression level of PDXK (figure 3A,B) and PAR (figure 3C,D) by cancer cells. Of note, we observed a positive correlation (Pearson test, $\mathrm{p}=0.002$ ) between DC-LAMP density and PDXK expression, as well as a significant $(\mathrm{p}=0.0034)$ negative correlation between CD8 density and PAR expression (figure $3 \mathrm{E}, \mathrm{F}$ ). $\mathrm{PAR}^{\text {high }} / \mathrm{PDXK}^{\text {low }}$ tumors showed a tendency for worse overall (figure $4 \mathrm{~A}$ ) and relapse-free (figure 4B) survival. These results suggest that tumor cell-intrinsic metabolic characteristics may affect local immunosurveillance.

\section{Immunological and metabolic characteristics of non-small cell lung cancer}

Intrigued by the aforementioned results, we decided to evaluate our observations in a different neoplastic disease, NSCLC, for which it was known that low expression of PDXK and high abundance of PAR are negative prognostic markers. ${ }^{70}$ Pearson analyses revealed a negative correlation $(\mathrm{p}=0.017)$ between PAR levels and $\mathrm{CD} 8^{+}$ $\mathrm{T}$ lymphocytes (figure $5 \mathrm{~A}$ ) and a positive trend $(\mathrm{p}=0.057$ ) between PDXK expression and infiltration by DC-LAMP ${ }^{+}$ cells (figure 5B). As expected, ${ }^{17} 18$ the detection of high levels of $\mathrm{CD}^{+}$or DC-LAMP ${ }^{+}$cells in tumors was associated with improved overall survival (figure 5C,D) (online supplemental table S4), and this effect was independent from age, gender, histology, smoking status and tumor stage in a multivariate Cox model $(\mathrm{p}=0.001$ and $<0.001$ for CD8 and DC-LAMP). The combined low infiltration by CD8 and DCs have a significantly worse prognosis compared with tumors highly infiltrated $(\mathrm{p}=0.0001$, logrank test) (figure $5 \mathrm{E}, \mathrm{F}$ ). Patients with $\mathrm{PAR}^{\text {high }} / \mathrm{PDXK}^{\text {low }}$ 
A

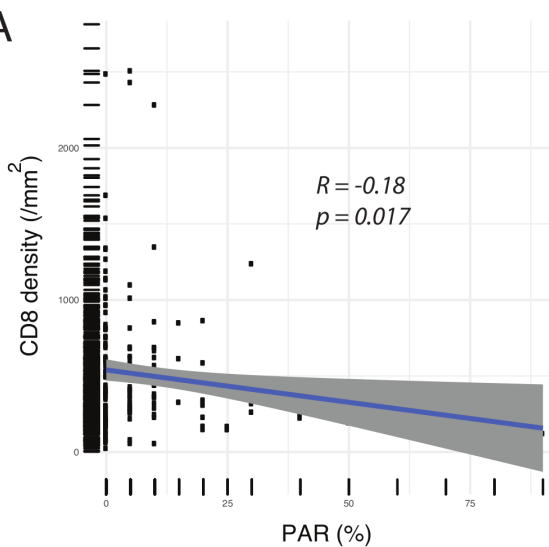

B

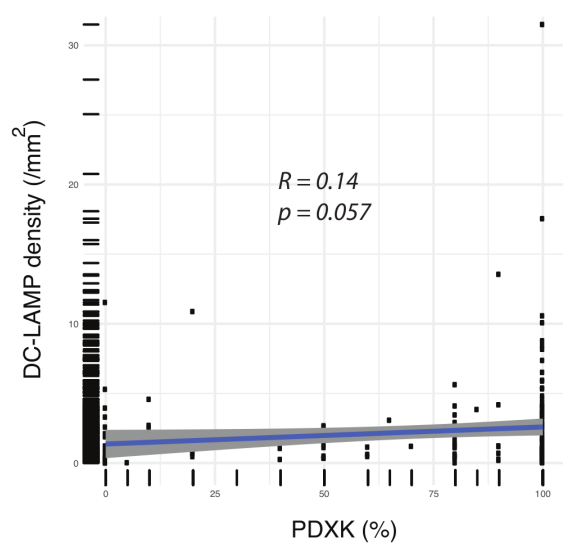

C CD8 and stage $\quad$ D

$-I-I I$ and $D C C^{\text {high }}+I-I I$ and $D C^{\text {low }}+I I I-I V$ and $D C^{\text {high }}+I I I-I V$ and $D C{ }^{\text {low }}$

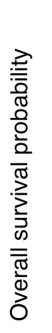

- III-IV and CD $8^{\text {high }} \Rightarrow$ III-IV and CD $8^{\text {low }}$
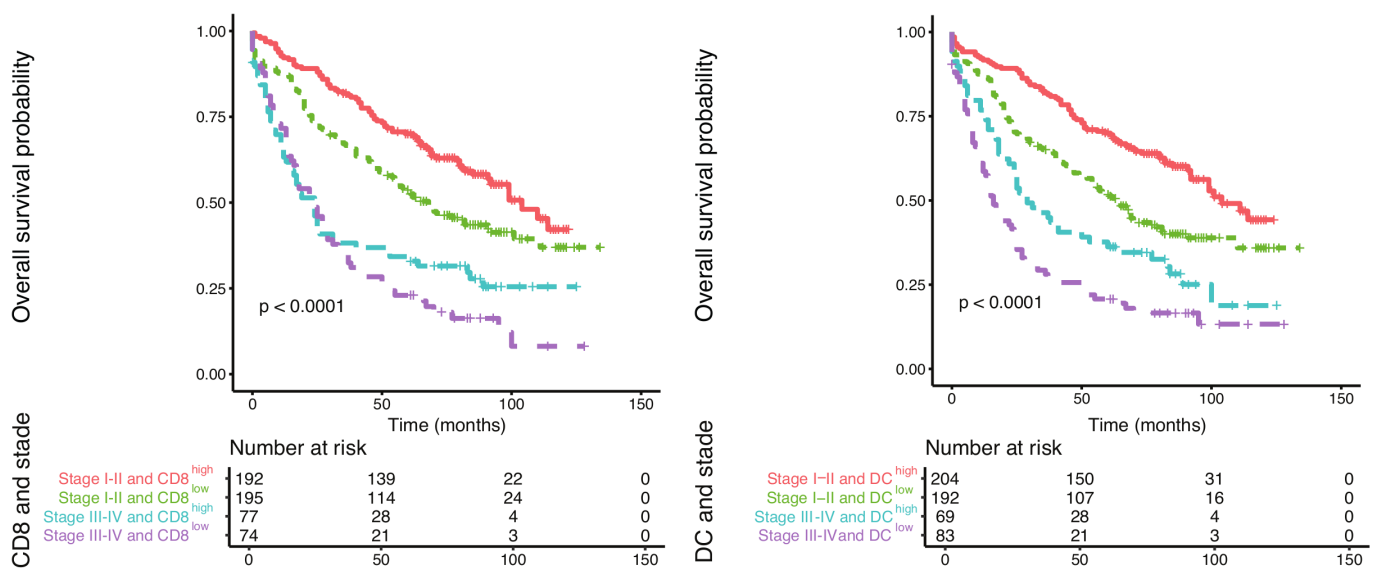

E

$\mathrm{CD} 8 / \mathrm{DC}$
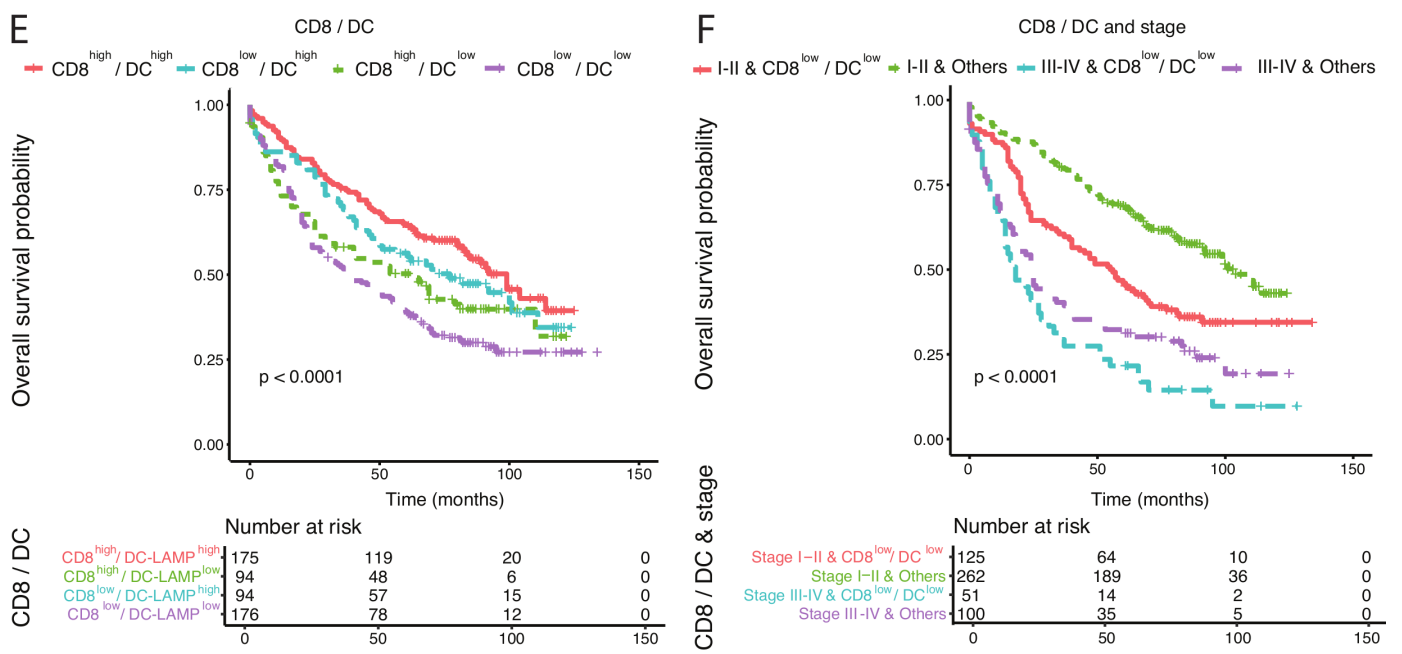

Figure 5 Prognostic value of CD8 and DC-LAMP stratification in patients with non-small-cell lung cancer. (A,B) Correlations between PAR/CD8 (A) $(n=184)$ and DC-LAMP/PDXK (B) $(n=186)$, respectively. The expression of PAR and PDXK by malignant cells was plotted against the density of CD8 and DC-LAMP, respectively, followed by calculation of Pearson's correlation coefficients. Each point represents one patient, with rug added on $X$ and $Y$ axes. (C,D) Kaplan-Meier curves of overall survival on stratification of patients according to CD8 and tumor stage (I-II vs III-IV) (C) or DC-LAMP and tumor stage (D) expression, respectively. (E,F) Kaplan-Meier curves of overall survival on stratification of patients according to combined CD8 and DC-LAMP (E) or CD8 ${ }^{\text {low }} / D C-L A M P^{\text {low }}$ status and tumor stage (I-II vs III-IV) (F) expression, respectively. P values were determined by means of the log-rank test. Tables summarize the number of patients at risk in each group at baseline and at several time points. Twoby-two comparisons show a significant survival advantage of CD8 infiltration in stage I-II ( $p=0.002$, OR=0.64 (0.48 to 0.86$)$ ) but not in stage III-IV ( $\mathrm{p}=0.3$, OR=0.82 (0.57 to 1.18)) tumors, and DC-LAMP infiltration in both stage I-II $(\mathrm{p}<0.001$, OR=0.58 $(0.44$ to $0.77)$ ) and stage III-IV ( $\mathrm{p}=0.02$, OR=0.65 (0.45 to 0.94$))$ tumors. CD8 $8^{\mathrm{low}} / \mathrm{DC}-\mathrm{LAMP} \mathrm{Iow}^{\mathrm{low}}$ tumors have a significantly poorer survival compared with other immune phenotypes in stage I-II $(p<0.001, \mathrm{OR}=1.24$ ( 0.85 to 1.81$)$ ) but not in stage III-IV $(p=0.1, O R=1.32$ (0.91 to 1.92)) tumors. DC-LAMP, dendritic cell lysosomal associated membrane glycoprotein; PAR, poly adenosine ribose; PDXK, pyridoxal kinase. 


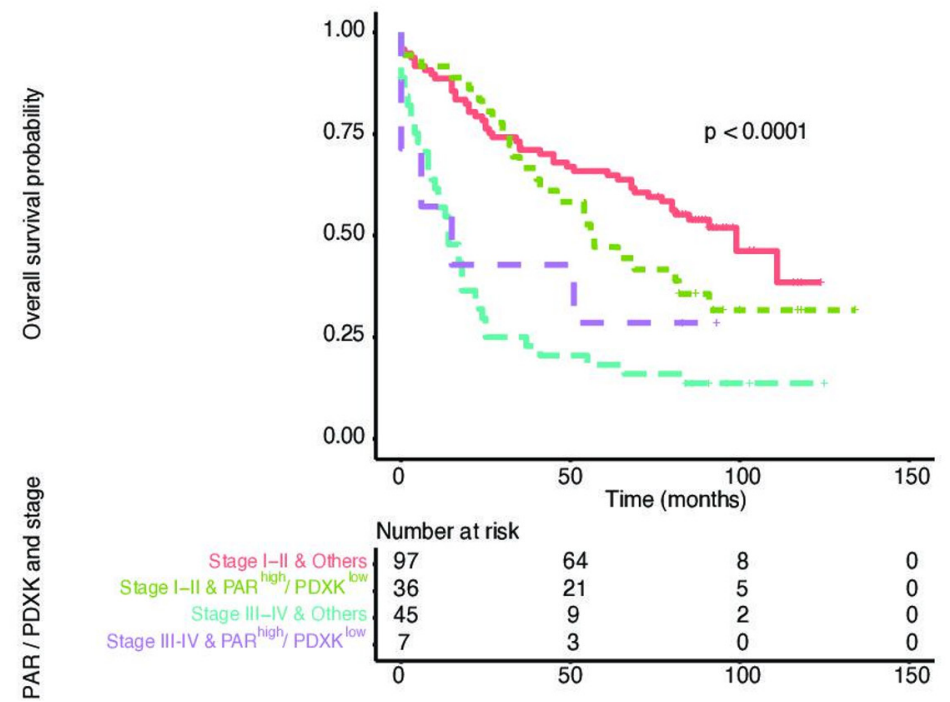

Figure 6 Kaplan-Meier curve of overall survival on stratification of patients with lung cancer according to tumor stage and $\mathrm{PAR}^{\text {high }} / \mathrm{PDXK} \mathrm{K}^{\mathrm{low}}$ status. $\mathrm{P}$ values were determined by means of the log-rank test. Tables summarize the number of patients at risk in each group at several time points. Two-by-two comparisons show a trend towards poorer overall survival in PAR ${ }^{\text {high/ }}$ PDXK ${ }^{\text {low }}$ tumors in stage I-II $(p=0.1)$ and not in stage III-IV $(p=0.6)$. PAR, poly adenosine ribose; PDXK, pyridoxal kinase.

cancers had a reduced overall survival, particularly in stage I-II tumors (figure 6), and this effect was independent from age, gender, histology, smoking status and tumor stage $(\mathrm{p}=0.02)$. Altogether, these results confirm the conjecture that tumor cell-intrinsic metabolic alterations may impact the composition of the local immune infiltrate.

\section{Cause-effect relationship between PARP1 activation and immunosuppression}

In human cervical and lung cancers, high abundance of PAR correlated with a reduced density of $\mathrm{CD} 8^{+} \mathrm{T}$ lymphocytes in the tumors. To establish a causal relationship between high PAR levels and reduced tumor immunosurveillance, we took advantage of Lewis lung cancer (LLC) cells (a mouse NSCLC cell line) that had been selected in vitro for cisplatin resistance, hence enhancing their capacity to maintain mitochondrial function and viability in vitro (figure 7A,B). Such cells manifested upregulation of PAR, as detectable by immunoblot analyses (figure 7C). Parental WT (online supplemental figure S1A,B) and cisplatin resistant $(\mathrm{R})$ clones were injected subcutaneously into mice and their immune infiltrate was characterized by immunofluorescence and flow cytometry (online supplemental figures S1C and S2) when the tumors had reached a surface of $1 \mathrm{~cm}^{2}$. Importantly, the density of $\mathrm{CD}^{+} \mathrm{T}$ cells was reduced for resistant $\left(\mathrm{PAR}^{\text {high }}\right)$ tumors $(p=0.028)$. Moreover, the LLC PAR ${ }^{\text {high }}$ tumors were less infiltrated in antigen presenting cells, (i) activated DCs

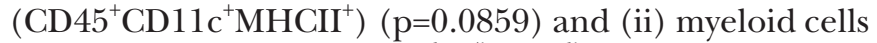
$\left(\mathrm{CD} 45^{+} \mathrm{CD} 11 \mathrm{~b}^{+} \mathrm{Ly}_{6 \mathrm{G}^{-}} \mathrm{Ly} \mathrm{C}^{\text {low/intermediate }}\right) \quad(\mathrm{p}=0.0012)$ as compared with their PAR ${ }^{\text {low }}$ counterparts (figure 7D-F). These results indicate that the metabolic phenotype of tumor cells may indeed shape the tumor microenvironment at the immunological level.

\section{DISCUSSION}

In an attempt to extend the general rule that oncometabolism may affect immunosurveillance, we have investigated the expression/activity of two enzymes, PDXK and PARP1, both implicated in the vitamin B metabolism, in the context of two distinct malignant diseases, cervical cancer and NSCLC. We observed that PDXK expression by malignant cells correlated with tumor infiltration by DCs, while PAR (which reflects PARP1 activity) anticorrelated with the local presence of CTLs. This is supported by transcriptional data for the positive correlation between myeloid DCs and PDXK and the negative correlation of T cells and PARP in patients with NSCLC. ${ }^{5}$ In mice, tumors formed by cisplatin-resistant $\mathrm{PAR}^{\text {high }}$ cells were scarcely infiltrated by $\mathrm{CD} 8^{+} \mathrm{T}$ lymphocytes, hinting to a potential link between the tumor-intrinsic changes in metabolism and the local immune tonus (rather than the selection of PAR ${ }^{\text {low }}$ cells by immunosurveillance). Hence, PARP1 and PDXK activity within tumor cells may influence the composition of the immune infiltrate.

Chemotherapies are rarely given with a curative intent in metastatic solid tumors. Cisplatin is a poor stimulator of anticancer immune responses when compared with other common chemotherapeutics including anthracyclines, cyclophosphamide, oxaliplatin and taxanes. ${ }^{19}$ Moreover, the scenario emerges that metabolic adaptations of cancer cells that render them cisplatin-resistant are actually contributing to immunosubversion. Thus, the downregulation of PDXK expression and activity 

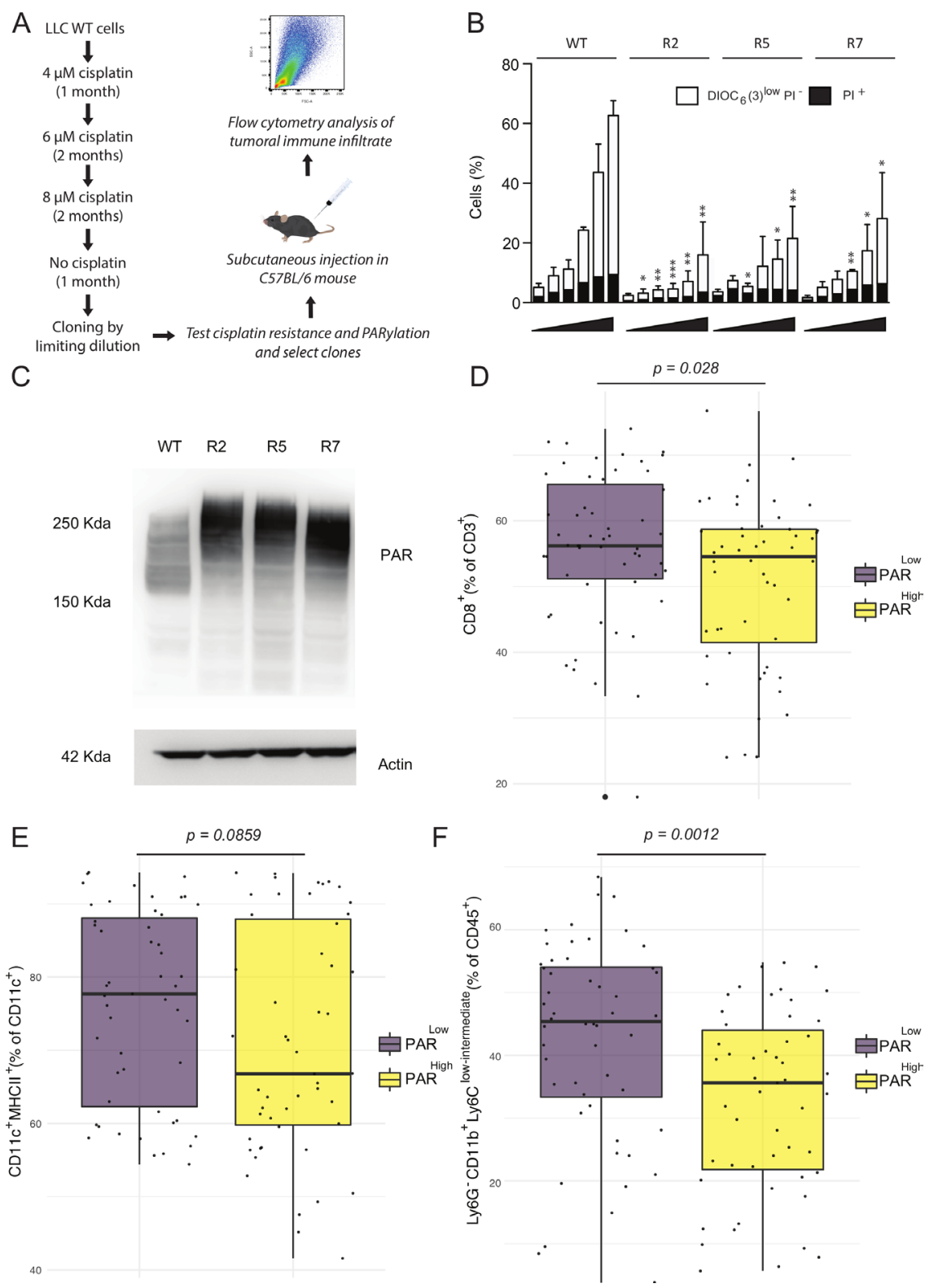

Figure 7 Immune infiltrate and PARP activity in a mouse lung cancer model. (A) Illustration of the strategy to obtain cisplatinresistant LLC cells, test cisplatin sensitivity and PARylation level, inject selected clones subcutaneously in C57BL/6 mice and analyze peritumoral immune infiltrate by flow cytometry. (B) Parental WT mouse LLC lung cancer cells and cisplatin-resistant derivatives $(\mathrm{R})$ were maintained in control conditions or treated with increasing concentrations of cisplatin $(5,10,20,30$ and $50 \mu \mathrm{mol} / \mathrm{L}$ ) for 48 hours. Thereafter, cells were subjected to the cytofluorometric assessment of apoptosis-related parameters on costaining with the vital dye PI and the mitochondrial membrane potential-sensing dye DiOC6(3). White and black columns illustrate the percentage of dying $\left[\mathrm{DiOC6}(3)\right.$ lowPI'] and dead $\left(\mathrm{PI}^{+}\right)$cells, respectively (means $\pm \mathrm{SEM}, \mathrm{n}=3$ ). ${ }^{*} \mathrm{P}<0.05 ;{ }^{* *} \mathrm{p}<0.01$ (Student t-test), compared with equally treated WT cells. (C) WT LLC cell line and R derivatives were cultured in normal growth medium and processed for the immunoblotting-based assessment of PAR-containing proteins. Actin levels were monitored to ensure equal loading of lanes. (D-F) Characterization of the T cell infiltrate in mouse lung cancers derived from PAR ${ }^{\text {high }}$ and parental PAR ${ }^{\text {low }}$ cells. C57BL/6 mice were injected subcutaneously with PAR $^{\text {low }}$ and PAR ${ }^{\text {high }}$ clones $(55$ and 53 mice, respectively;

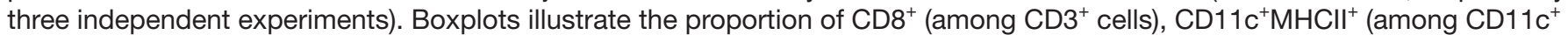
cells) and Ly6G ${ }^{-}$CD $11 b^{+}$Ly6 $6 C^{\text {low/intermediate }}$ (among CD45 ${ }^{+}$cells), respectively, in PAR ${ }^{\text {high }}$ and PAR ${ }^{\text {low }}$ tumors. $P$ values were calculated by Student's t test. ${ }^{*} P<0.05$, NS, non-significant, as compared with $T$ cell infiltrate in WT tumors. CD, cluster of differentiation; LLC, Lewis-lung cancer; PAR, poly adenosine ribose; PI, propidium iodide; WT, wild type.

may selectively diminish the recruitment of DCs (or their precursors) into the tumor bed. Moreover, high PARP1 activity may impede the infiltration of tumors by $\mathrm{CD} 8^{+} \mathrm{T}$ cells. Thus, cisplatin would cause cancer cell resistance to its cell-autonomous tumoricidal effects and alter the phenotype of cancer cells in a way that they escape from immunosurveillance. Of note, we have previously reported a synergy of cisplatin and the vitamin B6 precursor pyridoxine with LLC tumors that was only observed if the immune system was intact. ${ }^{20}$ Thus, 
metabolic manipulations of the tumors might impact their immune infiltration.

Admittedly, the mechanistic links between PDXK downregulation or PARP1 activation and local immunosubversion are elusive. However, from the pharmacological point of view, both alterations appear druggable. Thus, high-dose supplementation with pyridoxine (vitamin B6) does improve the tumor growth-reducing activity of cisplatin $^{20}$ and actually stimulates immunosurveillance, as we have recently shown for hormone-induced breast cancer. ${ }^{21}$ Moreover, it appears that PARP1 inhibition does cell-autonomously enhance DNA damage in cancer cells ${ }^{22}$ and increases the infiltration of tumors by $\mathrm{T}$ cells ${ }^{23-28}$ and sensitizes tumors to immune checkpoint blockade, as shown in mouse models ${ }^{27}$ and in human tumors. ${ }^{28}$ Obviously, the possibility to combine PARP inhibitors with immune checkpoint inhibitors is under active clinical investigation (NCT02571725 and NCT03598270). Mechanistically, DNA fragments generated in the context of inefficient DNA repair can activate the cGAS/STING pathway and elicit a Type-1 interferon response that has been well documented to enhance the production of $\mathrm{T}$ cell-recruiting chemokines. ${ }^{27}$ Extracellular PAR has been shown to activate Toll-like receptors 2 and 4, suggesting yet another possible link between oncometabolism and innate immune effectors. ${ }^{29}$ Perhaps more importantly, PARP1 activation may be expected to locally deplete NAD, which is consumed by PARP1, and supplementation with nicotinamide (which replenishes NAD) can stimulate anticancer immunosurveillance. ${ }^{21}$ In preclinical experiments, nicotinamide can be advantageously combined with PD-1 blocking antibodies to achieve tumor control. ${ }^{21}$ In essence, oncometabolic aberrations may yield novel actionable targets for improving cancer immunosurveillance.

The most important limitation of this study is the relatively low number of samples subjected to complete (clinical+metabolic+immunological) characterization, a weakness that is partially compensated for the fact that similar overall trends were found for two distinct cancer types, LACC and NSCLC. One limitation of this study is that the correlations between metabolic features (PDXK protein expression and PARP activity resulting into PAR accumulation) and features of immunosurveillance (presence of CD8+ T cells and DCs in the tumor) are relatively weak, perhaps reflecting the heterogeneity among the tumor types investigated in this paper. There are precedents for other metabolic properties of cancer (like the mRNA expression levels of aldehyde dehydrogenase 7 family member A1, ALDH7A1 and LIPC) correlates with the abundance of immune effectors in the tumor bed, ${ }^{5}$ suggesting that a whole series of metabolismrelated characteristics may affect (or be affected by) the local immune system. Future studies should validate the findings obtained in this work in prospective studies, in the context of state-of-the-art immunotherapies. If the conjecture that low PDXK and high PARP1 activities subvert anticancer immunosurveillance in patients can be confirmed, future combination trials that combine metabolism-targeting agents with immune checkpoint blockers might profit from a patient stratification that includes PDXK and PAR expression levels.

\section{Author affiliations}

${ }^{1}$ Equipe 11 labellisée par la Ligue contre le Cancer, Université de Paris, Sorbonne Université, INSERM U1138, Centre de Recherche des Cordeliers, INSERM, Paris, France

${ }^{2}$ Metabolomics and Cell Biology Platforms, Gustave Roussy Cancer Campus, Villejuif, France

${ }^{3}$ Faculté de médecine, Université de Paris Saclay, Kremlin Bicêtre, France ${ }^{4}$ INSERM U1030, Gustave Roussy, Université Paris-Saclay, Villejuif, France ${ }^{5}$ Pathology Department, Gustave Roussy Institute, Villejuif, Île-de-France, France ${ }^{6}$ INSERM U1030, Gustave Roussy, Université Paris-Saclay, INSERM, Villejuif, Val-deMarne, France

${ }^{7}$ Pathology Department, Gustave Roussy Institute, Villejuif, Val-de-Marne, France

${ }^{8}$ Pathology Department, Gustave Roussy Cancer Campus, Villejuif, France

${ }^{9}$ Centre d'Histologie, Imagerie cellulaire et Cytométrie (CHIC), Centre de Recherche des Cordeliers, Paris, Île-de-France, France

${ }^{10}$ Departments of Pathology and Thoracic Surgery, Hospital Cochin Assistance

Publique Hopitaux de Paris, APHP, Paris, Île-de-France, France

${ }^{11}$ Department of Thoracic Surgery, Hospital Cochin Assistance Publique Hopitaux de Paris, APHP, Paris, Île-de-France, France

${ }^{12}$ Department of Medical Oncology, Gustave Roussy Institute, Villejuif, île-de-France, France

${ }^{13}$ Department of Gynecologic Surgery, Gustave Roussy Institute, Villejuif, Île-deFrance, France

${ }^{14}$ Radiotherapy Department, Brachytherapy Unit, Gustave Roussy Institute, Villejuif, Val-de-Marne, France

${ }^{15}$ Sorbonne University, UMRS 1135, INSERM U1135, Centre d'Immunologie et des Maladies Infectieuses (Cimi-Paris), INSERM, Paris, Île-de-France, France

${ }^{16}$ INSERM U1138, Centre de Recherche des Cordeliers, Université de Paris,

Sorbonne Université, 75006 Paris, France

${ }^{17}$ Department of Medical Oncology, Gustave Roussy Cancer Campus, Villejuif, France

${ }^{18}$ Suzhou Institute for Systems Medicine, Chinese Academy of Medical Sciences, Suzhou, China

${ }^{19}$ Karolinska Institute, Department of Women's and Children's Health, Karolinska University Hospital, Stockholm, Sweden

${ }^{20}$ Pôle de Biologie, Hôpital Européen Georges Pompidou, Assistance PubliqueHôpitaux de Paris, Paris, France

\section{Twitter Adrien Joseph @AdrienJoseph9 and Isabelle Cremer @Cremerlsabelle}

Acknowledgements We thank Kariman Chaba for histopathological analyses.

Contributors MC, JM and GK designed the study, interpreted the results and wrote the manuscript. AJ, VA, JP, FO and AL performed the animal ad in vitro experiments. MM, NL, ML, JA, MCDN, IC, NB and AJ performed immunohistological analyses. AJ performed the statistical analysis. AL, PP, PM, SG, ED and CG enrolled patients and collected clinical and laboratory information. All of the authors critically reviewed and substantially improved the manuscript.

Funding GK is supported by the Ligue contre le Cancer (équipe labellisée); Agence National de la Recherche (ANR)—Projets blancs; ANR under the frame of E-Rare-2, the ERA-Net for Research on Rare Diseases; AMMICa US23/CNRS UMS3655; Association pour la recherche sur le cancer (ARC); Association "Ruban Rose"; Cancéropôle lle-de-France; Chancelerie des universités de Paris (Legs Poix), Fondation pour la Recherche Médicale (FRM); a donation by Elior; European Research Area Network on Cardiovascular Diseases (ERA-CVD, MINOTAUR); Gustave Roussy Odyssea, the European Union Horizon 2020 Project Oncobiome; Fondation Carrefour; High-end Foreign Expert Program in China (GDW20171100085), Institut National du Cancer (INCa); Inserm (HTE); Institut Universitaire de France; LeDucq Foundation; the LabEx Immuno-Oncology (ANR-18-IDEX-0001); the RHU Torino Lumière; the Seerave Foundation; the SIRIC Stratified Oncology Cell DNA Repair and Tumor Immune Elimination (SOCRATE); and the SIRIC Cancer Research and Personalized Medicine (CARPEM). AJ is supported by a grant from Fondation ARC pour la Recherche sur le Cancer. This study contributes to the IdEx Université de Paris ANR-18-IDEX-0001. ED, MM and ML are supported by INCa-DGOS TRANSLA 11-077. AnL is supported by a grant of ITM0 Cancer (Plan Cancer 2014-2019). 
Competing interests None declared.

Patient consent for publication Not required.

Provenance and peer review Not commissioned; externally peer reviewed.

Data availability statement Data are available on reasonable request.

Supplemental material This content has been supplied by the author(s). It has not been vetted by BMJ Publishing Group Limited (BMJ) and may not have been peer-reviewed. Any opinions or recommendations discussed are solely those of the author(s) and are not endorsed by BMJ. BMJ disclaims all liability and responsibility arising from any reliance placed on the content. Where the content includes any translated material, BMJ does not warrant the accuracy and reliability of the translations (including but not limited to local regulations, clinical guidelines, terminology, drug names and drug dosages), and is not responsible for any error and/or omissions arising from translation and adaptation or otherwise.

Open access This is an open access article distributed in accordance with the Creative Commons Attribution Non Commercial (CC BY-NC 4.0) license, which permits others to distribute, remix, adapt, build upon this work non-commercially, and license their derivative works on different terms, provided the original work is properly cited, appropriate credit is given, any changes made indicated, and the use is non-commercial. See http://creativecommons.org/licenses/by-nc/4.0/.

\section{ORCID iDs}

Adrien Joseph http://orcid.org/0000-0002-5278-8966

Isabelle Cremer http://orcid.org/0000-0002-0963-1031

\section{REFERENCES}

1 Fridman $\mathrm{WH}$, Zitvogel L, Sautès-Fridman C, et al. The immune contexture in cancer prognosis and treatment. Nat Rev Clin Oncol 2017; 14:717-34.

2 Hirsch L, Zitvogel L, Eggermont A, et al. PD-Loma: a cancer entity with a shared sensitivity to the PD-1/PD-L1 pathway blockade. Br J Cancer 2019;120:3-5.

3 Hanahan D, Weinberg RA. Hallmarks of cancer: the next generation. Cell 2011;144:646-74.

4 Huber V, Camisaschi C, Berzi A, et al. Cancer acidity: an ultimate frontier of tumor immune escape and a novel target of immunomodulation. Semin Cancer Biol 2017;43:74-89.

5 Stoll G, Kremer M, Bloy N, et al. Metabolic enzymes expressed by cancer cells impact the immune infiltrate. Oncoimmunology 2019;8:e1571389.

6 Lugini L, Matarrese P, Tinari A, et al. Cannibalism of live lymphocytes by human metastatic but not primary melanoma cells. Cancer Res 2006;66:3629-38.

7 Galluzzi L, Vitale I, Senovilla L, et al. Prognostic impact of vitamin B6 metabolism in lung cancer. Cell Rep 2012;2:257-69.

8 Michels J, Vitale I, Galluzzi L, et al. Cisplatin resistance associated with PARP hyperactivation. Cancer Res 2013;73:2271-80.

9 Michels J, Vitale I, Senovilla L, et al. Synergistic interaction between cisplatin and PARP inhibitors in non-small cell lung cancer. Cell Cycle 2013;12:877-83.

10 Michels J, Adam J, Goubar A, et al. Negative prognostic value of high levels of intracellular poly(ADP-ribose) in non-small cell lung cancer. Annals of Oncology 2015;26:2470-7.

11 Nedergaard BS, Ladekarl M, Thomsen HF, et al. Low density of CD3+, CD4+ and CD8+ cells is associated with increased risk of relapse in squamous cell cervical cancer. $\mathrm{Br} J$ Cancer 2007;97:1135-8.

12 Piersma SJ, Jordanova ES, van Poelgeest MIE, et al. High Number of Intraepithelial CD8 ${ }^{+}$Tumor-Infiltrating Lymphocytes Is Associated with the Absence of Lymph Node Metastases in Patients with Large Early-Stage Cervical Cancer. Cancer Res 2007;67:354-61.

13 Bethwaite PB, Holloway LJ, Thornton A, et al. Infiltration by immunocompetent cells in early stage invasive carcinoma of the uterine cervix: a prognostic study. Pathology 1996;28:321-7.

14 Schernberg A, Bockel S, Annede P, et al. Tumor shrinkage during chemoradiation in locally advanced cervical cancer patients: prognostic significance, and impact for image-guided adaptive brachytherapy. Int J Radiat Oncol Biol Phys 2018;102:362-72.

15 Fucikova J, Becht E, Iribarren K, et al. Calreticulin expression in human Non-Small cell lung cancers correlates with increased accumulation of antitumor immune cells and favorable prognosis. Cancer Res 2016;76:1746-56.

16 Olaussen KA, Adam J, Vanhecke E, et al. Parp1 impact on DNA repair of platinum adducts: preclinical and clinical read-outs. Lung Cancer 2013;80:216-22.

17 Dieu-Nosjean M-C, Antoine M, Danel C, et al. Long-Term survival for patients with Non-Small-Cell lung cancer with intratumoral lymphoid structures. Journal of Clinical Oncology 2008;26:4410-7.

18 Kawai O, Ishii G, Kubota K, et al. Predominant infiltration of macrophages and CD8 ${ }^{+} \mathrm{T}$ Cells in cancer nests is a significant predictor of survival in stage IV nonsmall cell lung cancer. Cancer 2008;113:1387-95.

19 Zitvogel L, Galluzzi L, Smyth MJ, et al. Mechanism of action of conventional and targeted anticancer therapies: Reinstating immunosurveillance. Immunity 2013;39:74-88.

20 Aranda F, Bloy N, Pesquet J, et al. Immune-dependent antineoplastic effects of cisplatin plus pyridoxine in non-small-cell lung cancer. Oncogene 2015;34:3053-62.

21 Buqué A, Bloy N, Perez-Lanzón M, et al. Immunoprophylactic and immunotherapeutic control of hormone receptor-positive breast cancer. Nat Commun 2020;11:3819.

22 Lord CJ, Ashworth A. Parp inhibitors: synthetic lethality in the clinic. Science 2017:355:1152-8.

23 Moreno-Lama L, Galindo-Campos MA, Martínez C, et al. Coordinated signals from PARP-1 and PARP-2 are required to establish a proper $\mathrm{T}$ cell immune response to breast tumors in mice. Oncogene 2020;39:2835-43.

24 Pantelidou C, Sonzogni O, De Oliveria Taveira M, et al. PARP Inhibitor Efficacy Depends on CD8 ${ }^{+}$T-cell Recruitment via Intratumoral STING Pathway Activation in BRCA-Deficient Models of Triple-Negative Breast Cancer. Cancer Discov 2019;9:722-37.

25 Ding L, Kim H-J, Wang Q, et al. Parp inhibition elicits STINGdependent antitumor immunity in BRCA1-deficient ovarian cancer. Cell Rep 2018;25:2972-80.

26 Wang Z, Sun K, Xiao Y, et al. Niraparib activates interferon signaling and potentiates anti-PD-1 antibody efficacy in tumor models. Sci Rep 2019;9:1853.

27 Sen T, Rodriguez BL, Chen L, et al. Targeting DNA damage response promotes antitumor immunity through STING-mediated T-cell activation in small cell lung cancer. Cancer Discov 2019;9:646-61.

28 Mehta AK, Cheney EM, Hartl CA, et al. Targeting immunosuppressive macrophages overcomes PARP inhibitor resistance in BRCA1associated triple-negative breast cancer. Nat Cancer 2021;2:66-82.

29 Krukenberg KA, Kim S, Tan ES, et al. Extracellular poly(ADPribose) is a pro-inflammatory signal for macrophages. Chem Biol 2015;22:446-52. 